\title{
ACHIEVING HIGH INPUT POWER FACTOR FOR DCM BUCK PFC CONVERTER BY VARIABLE DUTY-CYCLE CONTROL
}

\author{
A. Hakeem Memon \\ IICT, Mehran UET, Jamshoro. \\ E-mail: hakeem.memon@faculty.muet.edu.pk \\ M. Osama Nizamani \\ IICT, Mehran UET, Jamshoro. \\ E-mail: osama12el118@gmail.com \\ Anwar A. Memon \\ IICT, Mehran UET, Jamshoro. \\ E-mail: anwar.memon@faculty.muet.edu.pk \\ Zubair A. Memon \\ IICT, Mehran UET, Jamshoro. \\ E-mail: zubair.memon@faculty.muet.edu.pk \\ Amir M. Soomro \\ IICT, Mehran UET, Jamshoro. \\ E-mail: amir.soomro@faculty.muet.edu.pk
}

Recepción: 31/07/2019 Aceptación: 20/09/2019 Publicación: 06/11/2019

\section{Gitación sugerida:}

Memon, A.H., Nizamani, M.O., Memon, A.A., Memon, Z.A. y Soomro, A.M. (2019). Achieving high input power factor for DCM Buck PFG converter by variable Duty-Cycle Control. 3C Tecnología. Glosas de innovación aplicadas a la pyme. Edición Especial, Noviembre 2019, 185-199. doi: http://dx.doi.org/10.17993/3ctecno.2019.specialissue3.185-199

\section{Suggested citation:}

Memon, A.H., Nizamani, M.O., Memon, A.A., Memon, Z.A. \& Soomro, A.M. (2019). Achieving high input power factor for DCM Buck PFC converter by variable Duty-Cycle Control. 3C Tecnología. Glosas de innovación aplicadas a la pyme. Speciaal Issue, November 2019, 185-199. doi: http://dx.doi.org/10.17993/3ctecno.2019.specialissue3.185-199 


\section{ABSTRACT}

Buck power factor correction (PFC) converter is widely used for a broad range of AC/DC applications because of its many advantages However, the traditional discontinuous conduction mode (DCM) buck power factor correction converter (PFC) operates on constant duty-cycle control (CDCC) scheme, due to which its input power factor $(\mathrm{PF})$ is low. For improving PF near to unity, a variable-duty-cycle control (VDCC) method has been proposed. Fitting duty-cycle method is also introduced to make circuit implementation easier. For verifying the validity of proposed technique, the simulation results are carried out.

\section{KEYWORDS}

Variable duty-cycle control (VDCC), Constant duty-cycle control (CDCC), Discontinuous conduction mode (DCM), Power factor correction (PFG). 


\section{INTRODUCTION}

For achieving high power factor (PF) and low total harmonic distortion (THD), power factor correction (PFC) converters are normally used in most of ac-dc power conversion applications. PFC converters may be divided into active and passive types. Active PFC converters have more advantages as compared to passive ones in terms of high PF and small size (Memon, Yao, Chen, Guo, \& Hu, 2017). Various types of topologies and control schemes are available to implement the active PFC techniques. Amongst them, buck PFC converter is a good choice especially for a broad range of ac/dc applications due to its several advantages like high efficiency, cost reduction, low output voltage, and life time improvement. In literature, many researchers (Memon et al., 2017-2019) have introduced buck PFC converter as a preregulator. The buck ac-dc converter can overcome the disadvantages of the universal input condition. On the other hand, if this converter works in hard switching mode, switching losses will be higher especially at high input voltage that deteriorates the advantages of buck converter (Chiang \& Chen, 2009). The problem of hard switching mode can be overcome by operating it in critical conduction mode (CRM) or discontinuous conduction mode (DCM), which can provide zero voltage switching (ZVS) and reduce reverse recovery losses in diode (Yang, Wu, Zhang, \& Qian, 2010).

For modifying the performance of traditional buck converter, various researches have proposed various techniques and control schemes.

Endo, Yamashita, and Sugiura (1992) have introduced a high PF buck converter. Lee, Wang, and Hui (1997) have discussed modeling, analysis, and applications of buck converter in discontinuous input voltage mode operation. Huber, Gang, and Jovanovic (2010) have presented the performance evaluation on a clamped-current buck PFC converter. Jang and Jovanović (2011) have introduced a bridgeless buck PFC converter that substantially improves the efficiency at low line. Wu et al. (2011) have presented soft switched buck PFC converter operating with constant on-time control. Lamar, Fernandez, Arias, Hernando, and Sebastian (2012) have presented a tappedinductor high-brightness light-emitting diode (HB-LED) AC/DG driver operating in boundary conduction mode (BCM) for replacing incandescent bulb lamps. Wu et 
al. (2012) have put forward variable on-time control strategy to enhance the PF of buck converter. Xie, Zhao, Zheng, and Liu (2013) have proposed a new topology to enhance the PF. Yao et al., (2017) have proposed an injecting third harmonic method to realize high PF. Memon et al. (2017) have proposed a variable control scheme for integrated buck-flyback converter to enhance input PF.

In this paper, a variable duty-cycle control (VDCG) strategy is introduced for discontinuous conduction mode (DGM) buck converter to realize high input $\mathrm{PF}$.

The analysis of the operating principle of buck converter is discussed with traditional control (CDCG) scheme in Section 2. The VDGC is put forward in Section 3 to attain high PF. In Section 4, simulation results are discussed, and the conclusion is given in Section 5.

\section{OPERATION ANALYSIS OF DCM BUCK PFC CONVERTER}

The figure 1 illustrates the schematic diagram of a DCM buck PFC converter.

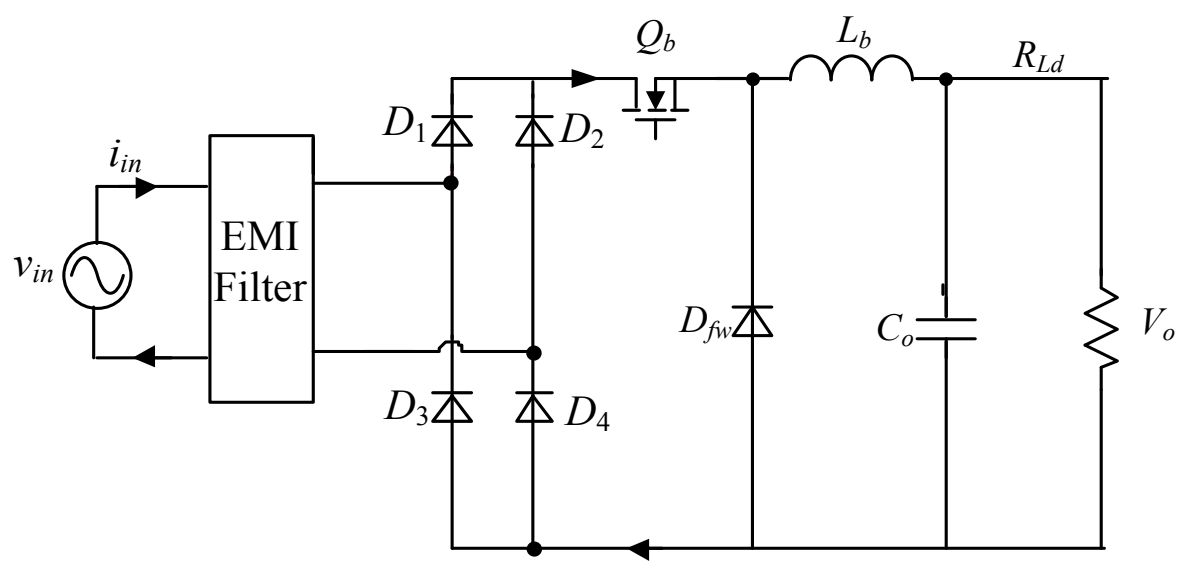

Figure 1. Schematic diagram of a DCM buck PFC converter.

The instantaneous and rectified input voltage during half line cycle can be given as:

$$
v_{i n}=v_{a}=V_{m} \sin \theta
$$


Whereas $V_{m}$ represent the input voltage amplitude, $\theta$ represent the input voltage angular frequency.

In switching cycle, peak current of inductor $i_{L b-p k}$ is:

$$
i_{L b_{-} p k}=\frac{V_{m} \sin \theta-V_{o}}{L_{b}} D_{y} T_{s}
$$

According to volt-second balance in the inductor:

$$
\left(V_{m} \sin \theta-V_{o}\right) D_{y} T_{s}=V_{o} D_{R} T_{s}
$$

Whereas $D_{y}$ represents duty-cycle, and $T_{s}$ represents switching cycle, $V_{o}$ represents voltage output and $D_{R}$ represents duty-cycle during turn off time of switch.

Re arranging Eq. no (3) we get:

$$
D_{R}=\frac{v_{g}-V_{o}}{V_{o}} D_{y}=\frac{V_{m} \sin \theta-V_{o}}{V_{o}} D_{y}
$$

The average value of inductor current is:

$$
i_{Q_{-} a v}=\frac{1}{2} i_{L b_{-} p k} D_{y}=\frac{\left(V_{m} \sin \theta-V_{o}\right) D_{y}^{2}}{2 L_{b} f_{s}}
$$

The input current of the buck converter can be expressed as:

$$
i_{\text {in }}= \begin{cases}\frac{\left(V_{m} \sin \theta-V_{o}\right) D_{y}{ }^{2}}{2 L_{b} f_{s}} & \theta_{0}<\theta<\pi-\theta_{0} \\ 0 & 0 \leq \theta<\theta_{0} \& \pi-\theta_{0}<\theta \leq \pi\end{cases}
$$

where $\theta 0=\arcsin \mathrm{Vo} / \mathrm{Vm}$ and Dy is constant.

The average input power with constant duty-cycle control (CDCG) is given as:

$$
P_{\text {in }}=\frac{1}{T_{\text {line }} / 2} \int_{0}^{T_{\text {tine }} / 2} v_{\text {in }} i_{\text {in }} d t=\frac{V_{m} D_{y}^{2}}{2 \pi L_{b} f_{s}} \int_{\theta_{0}}^{\pi-\theta_{o}} \sin \theta\left(\mathrm{V}_{m} \sin \theta-V_{o}\right) d \theta
$$


Whereas, $T_{\text {line }}$ represent the line cycle.

Suppose the converter's efficiency is $100 \%$, at that moment the duty-cycle is:

$$
D_{y}=\sqrt{\frac{2 \pi L_{b} f_{s} P_{o}}{V_{m} \int_{\theta_{0}}^{\pi-\theta_{o}} \sin \theta\left(\mathrm{V}_{m} \sin \theta-V_{o}\right) d \theta}}
$$

The input power factor $(\mathrm{PF})$ can be calculated from (6-8)

$$
P F=\frac{P_{i n}}{\frac{1}{\sqrt{2}} V_{m} I_{\text {in_rms }}}=\frac{\sqrt{\frac{2}{\pi}} \int_{\theta_{0}}^{\pi-\theta_{o}} \sin \theta(a \sin \theta-1) d \theta}{\sqrt{\int_{\theta_{0}}^{\pi-\theta_{o}}(a \sin \theta-1)^{2} d \theta}}
$$

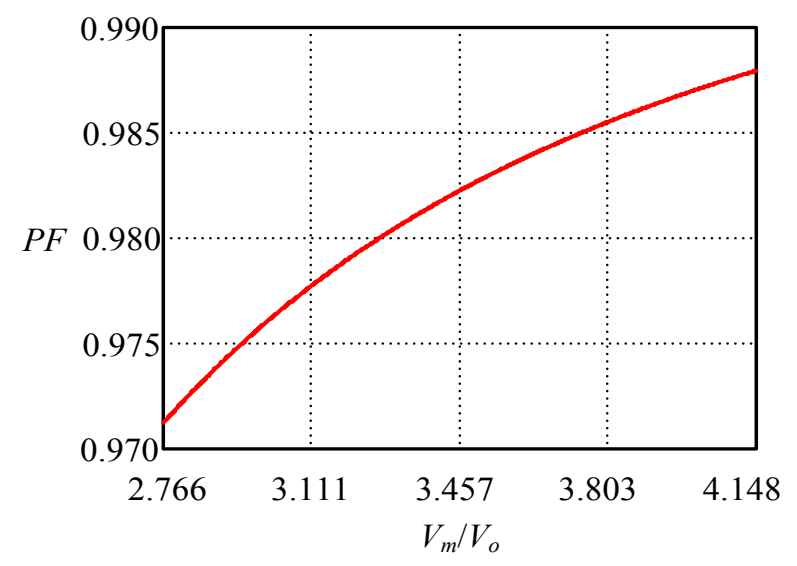

Figure 2. Relationship among the input PF and $a$.

Where $a=V_{m} / V_{o}$

The curve of input PF is drawn from (9) and is depicted in Figure 2. It can be observed that when the $V_{m} / V_{o}$ is greater, the $\mathrm{PF}$ is higher. When input voltage is 176VAC and output voltage is $90 \mathrm{~V}$, at that time PF is 0.971 . So, for achieving high $\mathrm{PF}$, a new control technique must be proposed. 


\section{PROPOSE CONTROL SCHEME TO ENHANCE INPUT PF}

\subsection{VARIABLE DUTY-CYCLE CONTROL TO REALIZE HIGH PF}

For realizing unity PF, the variation rule for duty-cycle must be:

$$
D_{y}=\sqrt{\frac{D_{0} V_{m} \sin \theta}{V_{m} \sin \theta-V_{o}}} \quad \theta_{0}<\theta<\pi-\theta_{0}
$$

where $D_{o}$ is a co-efficient,

By replacing the value of $D_{y}$ in (7), we get:

$$
i_{\text {in }}=\frac{D_{0} V_{m} \sin \theta}{2 L_{b} f_{s}} \quad \theta_{0}<\theta<\pi-\theta_{0}
$$

Eq. (11) shows that input current is pure sinusoidal and hence unity PF can be realized.

The average input power with proposed control scheme is given as:

$$
P_{i n}=\frac{1}{\pi} \int_{\theta_{0}}^{\pi-\theta_{0}} V_{m} \sin \theta \cdot \frac{D_{0} T_{s} V_{m} \sin \theta}{2 L_{b}} d \theta=P_{o}
$$

From (13), $D_{0}$ can be obtained as:

$$
D_{0}=\frac{4 \pi L_{b} f_{s} P_{o}}{\mathrm{~V}_{m}^{2}\left(\pi-2 \theta_{0}+\sin 2 \theta_{0}\right)}
$$

By putting (13) into (11) leads to:

$$
D_{y}= \begin{cases}\sqrt{\frac{4 \pi P_{o} L_{b} f_{s} \sin \theta}{\mathrm{V}_{m}\left(\pi-2 \theta_{0}+\sin 2 \theta_{0}\right)\left(V_{m} \sin \theta-V_{o}\right)}} & \theta_{0}<\theta<\pi-\theta_{0} \\ 0 & 0 \leq \theta<\theta_{0} \& \pi-\theta_{0}<\theta \leq \pi\end{cases}
$$




\subsection{THE FITTING DUTY CYCLE}

The subtraction, multiplication, division and root operation included, the dutycycle expressed in (14) is complicated to be realized by analog circuit. Therefore, it is necessary to simplify (14).

Defining $a=V_{m} / V_{v}, y=\sin \theta,(14)$ can be rewritten as:

$$
D_{y}= \begin{cases}\sqrt{\frac{D_{0} a y}{\mathrm{a} y-1}} & \theta_{0}<\theta<\pi-\theta_{0} \\ 0 & 0 \leq \theta<\theta_{0} \& \pi-\theta_{0}<\theta \leq \pi\end{cases}
$$

Based on Taylor's series:

$$
f(x)=f\left(x_{0}\right)+f^{\prime}\left(x_{0}\right)\left(x-x_{0}\right)+\frac{1}{2 !} f^{\prime \prime}\left(x_{0}\right)\left(x-x_{0}\right)^{2}+\cdots+\frac{1}{n !} f^{(n)}\left(x_{0}\right)\left(x-x_{0}\right)^{n}+\cdots
$$

Eq. (16) can be expressed as:

$$
D_{y}=\sqrt{a D_{0}} \cdot\left[\sqrt{\frac{y_{0}}{a y_{0}-1}}-\frac{1}{2} \cdot\left(\frac{y_{0}}{a y_{0}-1}\right)^{-\frac{1}{2}} \cdot \frac{1}{\left(a y_{0}-1\right)^{2}} \cdot\left(y-y_{0}\right)+\ldots\right] \quad \theta_{0}<\theta<\pi-\theta_{0}
$$

Keeping first derivative element, (17) is approximated as:

$$
D_{y_{-} f t}=\sqrt{\frac{D_{0} a y_{0}}{a y_{0}-1}} \cdot \frac{2 a y_{0}-1}{2\left(a y_{0}-1\right)} \cdot\left(1-\frac{y}{2 a y_{0}^{2}-y_{0}}\right)=D_{1} \cdot\left(1-\frac{y}{2 a y_{0}^{2}-y_{0}}\right) \quad \theta_{0}<\theta<\pi-\theta_{0}
$$

where $D_{1}=\sqrt{\frac{D_{0} a y_{0}}{a y_{0}-1}} \cdot \frac{2 a y_{0}-1}{2\left(a y_{0}-1\right)}$.

Substitution (18) into (6) and (7), respectively, leads to:

$$
i_{i n_{-} V D C C}=\frac{V_{o} D_{1}^{2}(a \sin \theta-1)\left(1-\frac{y}{2 a y_{0}^{2}-y_{0}}\right)^{2}}{2 L_{b} f_{s}} \quad \theta_{0}<\theta<\pi-\theta_{0}
$$




$$
P_{i n_{-} V D C C}=P_{o}=\frac{V_{m} V_{o} D_{1}^{2}}{2 \pi L_{b} f_{s}} \int_{\theta_{0}}^{\pi-\theta_{o}} \sin \theta(a \sin \theta-1)\left(1-\frac{\sin \theta}{2 a y_{0}{ }^{2}-y_{0}}\right)^{2} d \theta
$$

From (19) and (20), input PF is calculated as:

$$
P F=\frac{P_{\text {in }}}{V_{\text {in_rms }} I_{\text {in_rms }}}=\frac{\int_{\theta_{0}}^{\pi-\theta_{o}} \sqrt{\frac{2}{\pi}} \sin \theta\left(2 a y_{0}{ }^{2}-y_{0}-\sin \theta\right)^{2}(a \sin \theta-1) d \theta}{\sqrt{\int_{\theta_{0}}^{\pi-\theta_{0}}\left(2 a y_{0}{ }^{2}-y_{0}-\sin \theta\right)^{4}(a \sin \theta-1)^{2} d \theta}}
$$

If the input voltage range is 176-220 VAC, output voltage is $90 \mathrm{~V}$. Replacing $a=$ $176 \sqrt{2} / 90$ into (21), and differentiating (21) with $y_{0}$, also setting it to zero, $y_{0}=0.75$ is obtain.

Substituting $y_{0}=0.75$ into (19), the expression of duty cycle is:

$$
D_{y_{-} f t}=D_{1} \cdot \frac{1.125 V_{m}-0.75 V_{o}-V_{o} \sin \theta}{1.125 V_{m}-0.75 V_{o}} \quad \theta_{0}<\theta<\pi-\theta_{0}
$$

\subsection{IMPLEMENTATION OF THE CONTROL CIRCUIT}

The implementation of control circuit is presented in Figure 3. The dotted line represents the variable-duty cycle scheme. The rectified input voltage is detected by a voltage divider of $R_{1}$ and $R_{2}$, and $v_{g f}=k_{v g} V_{m} \sin \theta$, however $k_{v g}$ is the voltage sensor gain. $R_{3}, D_{1}, C_{1}$ and $R_{4}$ are the circuit to gain the peak value of the rectified input voltage, i.e., $v_{B}=k_{v g} \cdot \mathrm{V}_{m}$. The output voltage is detected by a voltage divider compared of $R_{5}$ and $R_{6}$, the voltage sensor gain is deliberately set to $0.353 k_{v g}$, so $v_{\text {of }}$ $=0.353 k_{v g} V_{o}$. Letting $R_{g}=1.125 R_{7}$, then, and letting $R_{g}=R_{10}=R_{13}=R_{14}$, and $R_{12}=2.833$ $R_{11}$, then, the error amplifier can be regulated by output voltage, the output voltage can sense through a voltage divider of $R_{15}$ and $R_{16}$ related to reference voltage $V_{o g}$. $R_{17}$ and $C_{2}$ form the compensation system. $v_{x}, v_{z}$ and $v_{E A}$ are sent to the multiplier, and $v_{P}=v_{E A} \frac{0.75 V_{o}-1.125 V_{m}+V_{o} \sin \theta}{0.75 V_{o}-1.125 V_{m}} . v_{P}$ is given to comparator and compared with the sawtooth carrier, and the comparators output calculate the required duty-cycle, 
which changes as in eq. no (22), whereas $v_{E A}$ and sawtooth amplitude calculate the coefficient $D_{l}$.

Through VDCG, the DCM buck PFC converter output voltage is operated at $90 \mathrm{~V}$. Now $V_{\text {og }}$ is set by $5 \mathrm{~V}$, then the output voltage sense gain can set at $1 / 18$, i.e., $R_{15}=$ $17 R_{16}$.

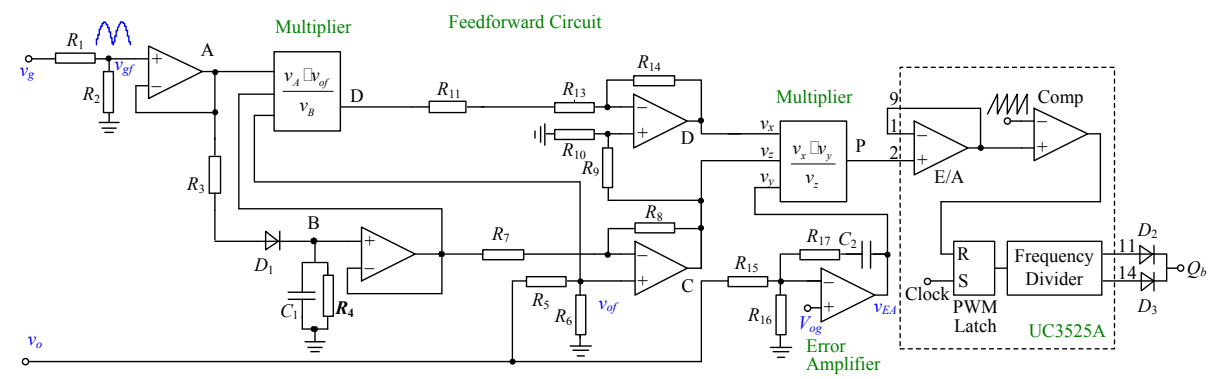

Figure 3. Control circuit of the variable duty-cycle control.

\section{ADVANTAGES OF PROPOSED CONTROL SCHEME}

\subsection{IMPROVEMENT OF THE INPUT PF}

From (9) and (21), the input PF curves with a CDCG and a VDCG are drawn and are depicted in Figure 4. It can be observed that VDCG improve the input PF. Once the input voltage is set at $176 \mathrm{VAC}$, the $\mathrm{PF}$ is improved from 0.971 to 0.983 .

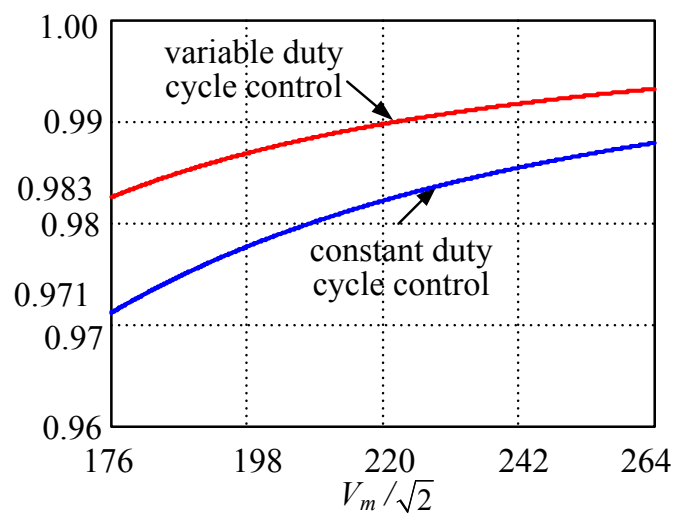

Figure 4. Comparison of the input between proposed and traditional control. 


\section{SIMULATION VERIFICATION}

For verifying the effectiveness of VDCG strategy, simulations are carried out. The input voltage range is $176-264 \mathrm{VAC}$, and the output is $90 \mathrm{~V}$. For ensuring the current to be in DCM, UC3525A IC is used. All the components in the circuit are selected as idea.

Figure 5 and Figure 6 show the simulation waveforms of $v_{i n}, i_{i n}$, and $v_{o}$ of buck converter with CDCG and VDCG at 176VAC inputs, respectively. It can be observed that the input current with VDCG is more sinusoidal as compared with CDCG.

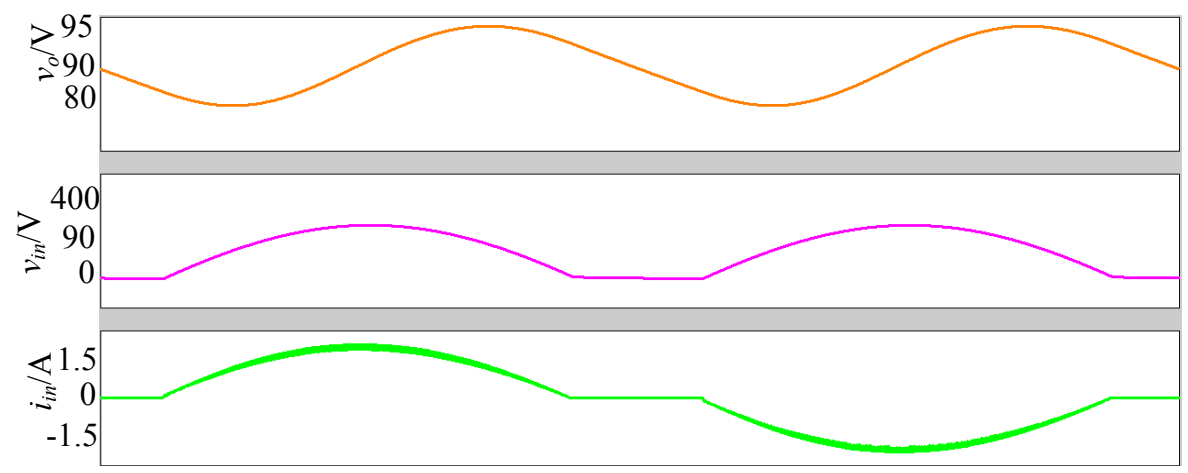

Figure 5. $v_{\text {in }}, \mathrm{i}_{\text {in }}$, and $v_{o}$ with CDCC.

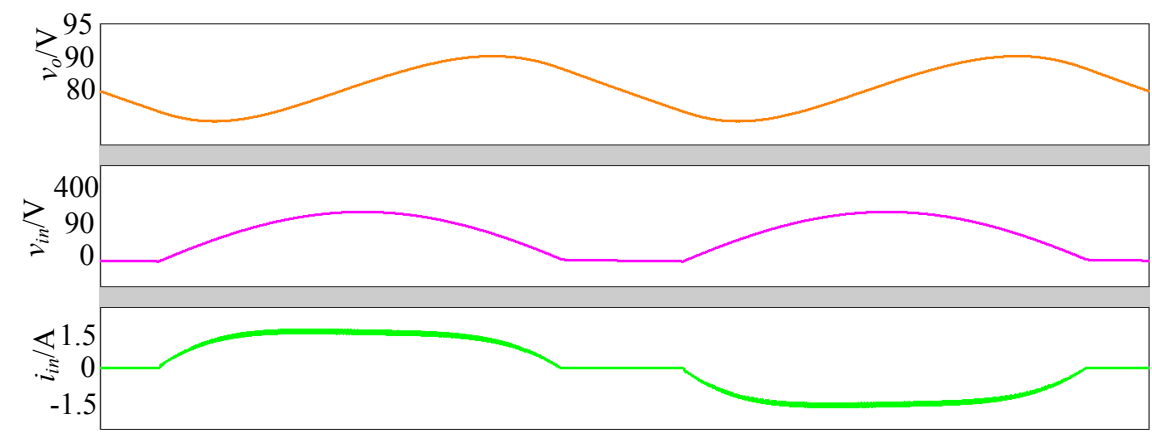

Figure 6. $v_{\text {in }}, \mathrm{i}_{\text {in }}$, and $v_{o}$ with VDCC. 


\section{CONCLUSION}

With constant duty-cycle control, the input power factor of discontinues conduction mode buck converter is low especially at low input voltages. A variable duty-cycle control scheme and the implementation circuit are proposed to realize high power factor. Simulation results are presented for the verification of the analysis.

\section{REFERENCES}

Ghiang, G. Y., \& Ghen, G. L. (2009). Zero-voltage-switching control for a PWM buck converter under DCM/CGM boundary. IEEE Transactions on Power Electronics, 24(9), 2120-2126. doi: https://doi.org/10.1109/TPEL.2009.2021186

Endo, H., Yamashita, T., \& Sugiura, T. (1992). A high-power-factor buck converter. PESC '92 Record. 23rd Annual IEEE Power Electronics Specialists Conference, 1071-1076 vol. 2. doi: https://doi.org/10.1109/PESG.1992.254766

Huber, L., Gang, L., \& Jovanovic, M. M. (2010). Design-oriented analysis and performance evaluation of buck PFG front end. IEEE Transactions on Power Electronics, 25(1), 85-94. doi: https://doi.org/10.1109/TPEL.2009.2024667

Jang, Y., \& Jovanović, M. M. (2011). Bridgeless high-power-factor buck converter. IEEE Transactions on Power Electronics, 26(2), 602-61 1. doi: https:/ / doi.org/ 10.1109 / TPEL.2010.2068060

Lamar, D. G., Fernandez, M., Arias, M., Hernando, M. M., \& Sebastian, J. (2012). Tapped-inductor buck HB-LED AC-DG driver operating in boundary conduction mode for replacing incandescent bulb lamps. IEEE Transactions on Power Electronics, 27(10), 4329-4337. doi: https:/ / doi.org/10.1109/TPEL.2012.2190756

Lee, Y. S., Wang, S.J., \& Hui, S. Y. R. (1997). Modeling, analysis, and application of buck converters in discontinuous-input-voltage mode operation. IEEE Transactions on Power Electronics, 12(2), 350-360. doi: https:/ / doi.org/10.1109/63.558762 
Memon, A. H., \& Yao, K. (2018). UPG strategy and implementation for buckbuck/boost PF correction converter. IET Power Electronics, 11(5), 884-894. doi: https://doi.org/10.1049/iet-pel.2016.0919

Memon, A. H., Baloach, M. H., Sahito, A. A., Soomro, A. M., \& Memon, Z. A. (2018). Achieving High Input PF for CRM Buck-Buck/Boost PFC Converter. IEEE Access, 6, 79082-79093. doi: https://doi.org/10.1109/ ACGESS.2018.2879804

Memon, A. H., Memon, Z. A., Shaikh, N. N., Sahito, A. A., \& Hashmani, A. A. (2019). Boundary conduction mode modified buck converter with low input current total harmonic distortion. Indian Fournal of Science and Technology, 12(17). doi: https://doi.org/10.17485/ijst/2019/v12i17/144613

Memon, A. H., Pathan, A. A., Kumar, M., Sahito, A. A J., \& Memon, Z. A. (2019). Integrated buck-flyback converter with simple structure and unity power factor. Indian Fournal of Science and Technology, 12(17). doi: https://doi.org/10.17485/ ijst/2019/v12i17/144612

Memon, A. H., Shaikh, N. N., Kumar, M., \& Memon, Z. A. (2019). Buck-buck/ boost converter with high input power factor and non-floating output voltage. International Fournal of Computer Science and Network Security, 19(4), 299-304. Retrieved from: http://paper.ijcsns.org/07_book/201904/20190442.pdf

Memon, A. H., Yao, K., Ghen, Q., Guo, J., \& Hu, W. (2017). Variable-on-time control to achieve high input power factor for a CRM-integrated buck-flyback PFG converter. IEEE Transactions on Power Electronics, 32(7), 5312-5322. doi: https://doi.org/10.1109/TPEL.2016.2608839

Wu, X., Yang, J., Zhang,J., \& Qian, Z. (2011). Variable on-time (VOT)-controlled critical conduction mode buck PFC converter for high-input AC/DG HB-LED lighting applications. IEEE Transactions on power Electronics, 27(1 1), 4530-4539. doi: https://doi.org/10.1109/TPEL.2011.2169812 
Wu, X., Yang, J., Zhang, J., \& Xu, M. (2011). Design considerations of softswitched buck PFG converter with constant on-time (COT) control. IEEE Transactions on Power Electronics, 26(11), 3144-3152. https://doi.org/10.1109/ TPEL.2011.2145391

Xie, X., Zhao, G., Zheng, L., \& Liu, S. (2012). An improved buck PFC converter with high power factor. IEEE Transactions on power electronics, 28(5), 2277-2284. doi: https://doi.org/10.1109/TPEL.2012.2214060

Yang, J., Wu, X., Zhang, J., \& Qian, Z. (2010). Design considerations of a high efficiency ZVS buck AC-DC converter with constant on-time control. Intelec 2010, 1-5. doi: https://doi.org/10.1109/intlec.2010.5525720

Yao, K., Zhou, X., Yang, F., Yang, S., Cao, G., \& Mao, G. (2017). Optimum third current harmonic during nondead zone and its control implementation to improve PF for DCM buck PFG converter. IEEE Transactions on Power Electronics, 32(12), 9238-9248. doi: https://doi.org/10.1109/TPEL.2017.2657883 
Edición Especial Special Issue Noviembre 2019

DOI: http://dx.doi.org/10.17993/3ctecno.2019.specialissue3.185-199 